\title{
Retraction Note to: Isolated central retinal artery occlusion as an initial presentation of paroxysmal nocturnal hemoglobinuria and successful long-term prevention of systemic thrombosis with eculizumab (Jpn J Ophthalmol. 2013;57:424-8)
}

\author{
Hyun Seung Yang $\cdot$ So Hyun Park • \\ Jung Ran Choi $\cdot$ June-Gone Kim
}

Published online: 1 March 2014

(C) Japanese Ophthalmological Society 2014

\section{Retraction to: Jpn J Ophthalmol (2013) 57:424-8 DOI 10.1007/s10384-013-0252-x}

The article "Isolated central retinal artery occlusion as an initial presentation of paroxysmal nocturnal hemoglobinuria and successful long-term prevention of systemic thrombosis with eculizumab" by Hyun Seung Yang, So Hyun Park, Jung Ran Choi and June-Gone Kim was published in the Japanese Journal of Ophthalmology in 2013;57:424-428. (DOI 10.1007/s10384-013-0252-x). Dr. Yang and co-authors have informed the Editors of this Journal that critical data in the article were not valid. Specifically, major errors were found in Case 2, which formed a key component of the article. Accordingly, the article is hereby retracted, with apologies from the authors.

The online version of the original article can be found under doi:10.1007/s10384-013-0252-x.

\section{H. S. Yang · J.-G. Kim $(\bowtie)$}

Department of Ophthalmology, Asan Medical Center,

388-1 Pungnap-2 dong, Songpa-gu, Seoul 138-736, Korea

e-mail: junekim@amc.seoul.kr

S. H. Park · J. R. Choi

Department of Internal Medicine, Seoul Central Veterans

Hospital, Seoul, Korea 